ON

\title{
PARACENTESIS THORACIS
}

AS A CURATIVE MEASURE IN EMPYEMA AND INFLAM-

MATORY HYDROTHORAX.

By HAMILTON ROE, M.D., Oxon.,

gENIOR PHYSICIAN TO THE WESTMINSTER HOSPITAL, AND PHYSICIAN

TO THE HOSPITAL FOR DISEASES OF THE CHEST.

READ APRIL 23RD, 1844.

The opinion very generally prevails amongst the most eminent members of our profession, that the operation of tapping the chest is one which affords but little hope of curing either empyema or hydrothorax; and, therefore, that it should never be performed until the difficulty of breathing, caused by the pressure of the fluid effused into the pleural cavity, becomes so urgent as to threaten immediate death. The reasons assigned for this opinion are-

First-that the re-accumulation of fluid will commence immediately after its evacuation has been effected, and can be prevented by the action of the absorbents only; and, therefore, that we ought to rely upon them, in the first instance, for its removal.

Secondly-that the operation itself is attended with very considerable danger. And, 
Thirdly-that the majority of those cases in which the operation has been performed, has terminated fatally.

The names of Boyer, Dupuytren, Sir Astley Cooper, Laennec, Townsend, Gendrin, and Stokes, are found amongst those who speak unfavourably of paracentesis thoracis, and as no modern physician or surgeon has recommended it as a curative measure, it cannot excite surprise that it should have fallen, as it has done, into very general disrepute, inasmuch as the judgment of a large portion of the profession must, in the absence of personal experience, be influenced by the opinions of men of such high standing. To ascertain how far the objections to it were derived from the results which followed its performance, I collected all the cases of this operation which had been published in the English language, between the years 1812 and 1832 inclusive, presuming that the knowledge of auscultation and percussion had by that time become so general, as to ensure tolerable accuracy of diagnosis, and I found that the recoveries were to the deaths, in the proportion of twenty-eight to eleven. These cases are arranged in a tabular form, and certain particulars are stated in separate columns, to enable the Society to form a judgment of the causes of the failure or success of the operation. 


\begin{tabular}{|c|c|c|c|c|c|c|c|c|c|c|c|}
\hline 迩 & 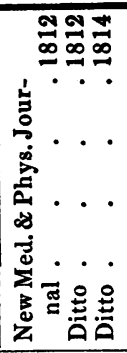 & 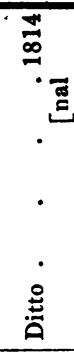 & 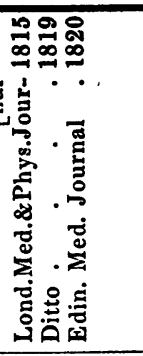 & 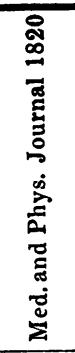 & 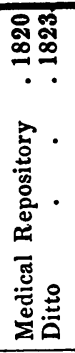 & 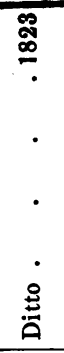 & 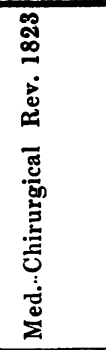 & $\stackrel{\leftrightarrow}{\circ}$ & : & 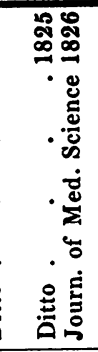 & 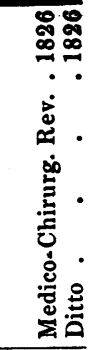 \\
\hline 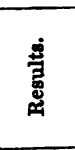 & 总 䎡 & లెّ & 总芯芯 & 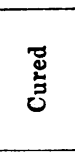 & 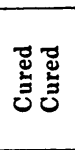 & 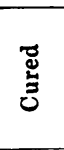 & 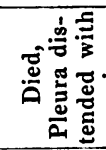 & . & 苋 & نَّ & 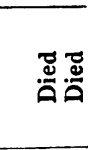 \\
\hline 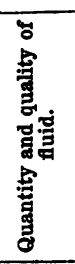 & 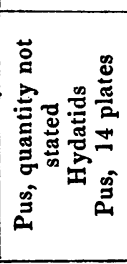 & 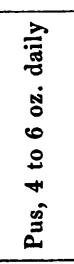 & 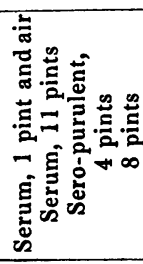 & 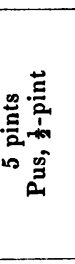 & 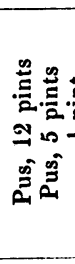 & 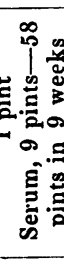 & 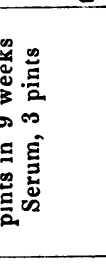 & i. & 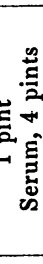 & 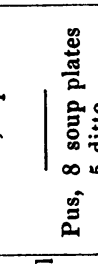 & 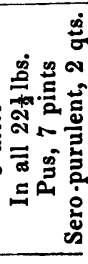 \\
\hline 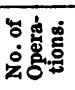 & $\Rightarrow \quad \rightarrow-$ & - & $\neg-\infty$ & - & $\rightarrow \infty$ & N & - & N & $\rightarrow$ & 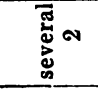 & $\rightarrow$ \\
\hline 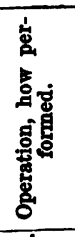 & 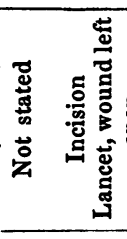 & 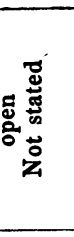 & 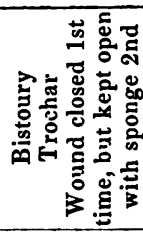 & 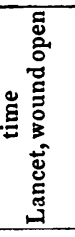 & 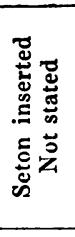 & 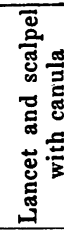 & 势 & 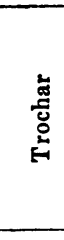 & 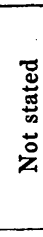 & 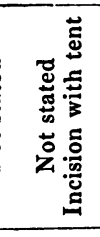 & \\
\hline 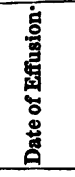 & 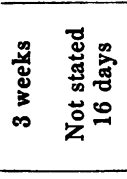 & $\begin{array}{l}\infty \\
\frac{x}{2} \\
0 \\
0 \\
0\end{array}$ & 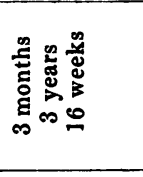 & 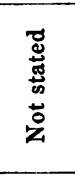 & 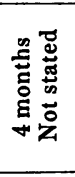 & 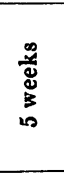 & 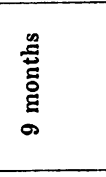 & 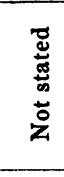 & 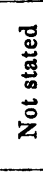 & 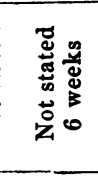 & 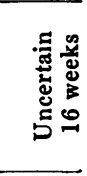 \\
\hline \&. & ๑ : ని & 1 & ซึซ & 2 & ణొ & م & $\mathscr{m}$ & สิ & 1 & 11 & $\Re$ \\
\hline 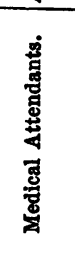 & 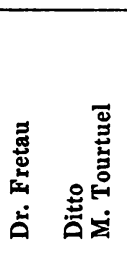 & 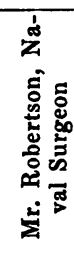 & 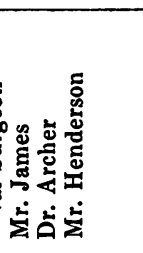 & 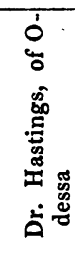 & 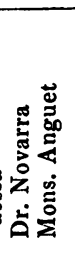 & 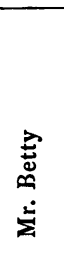 & 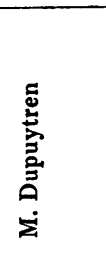 & 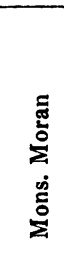 & 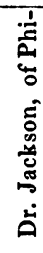 & 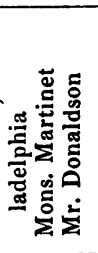 & 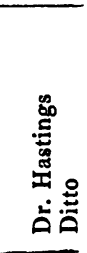 \\
\hline 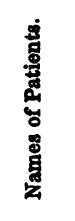 & 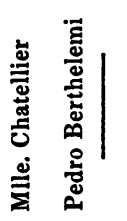 & $\begin{array}{l}\dot{\theta} \\
\dot{H}\end{array}$ & ن & & 苋 & 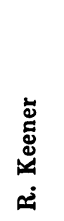 & 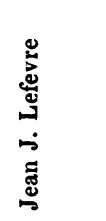 & 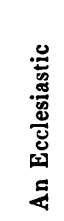 & $\begin{array}{l}\circ \\
\text { ¿0 } \\
4 \\
4\end{array}$ & 苛 & 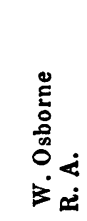 \\
\hline$\dot{8}$ & - N & + & asor & $\infty$ & 요으 & $=$ & શ & $\dddot{2}$ & $\Xi$ & $\mathscr{2}$ & \\
\hline
\end{tabular}




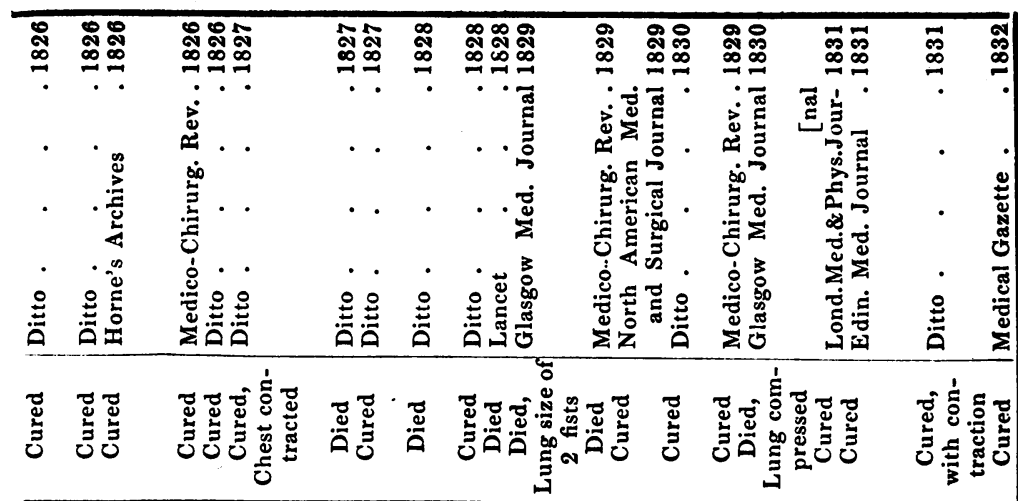

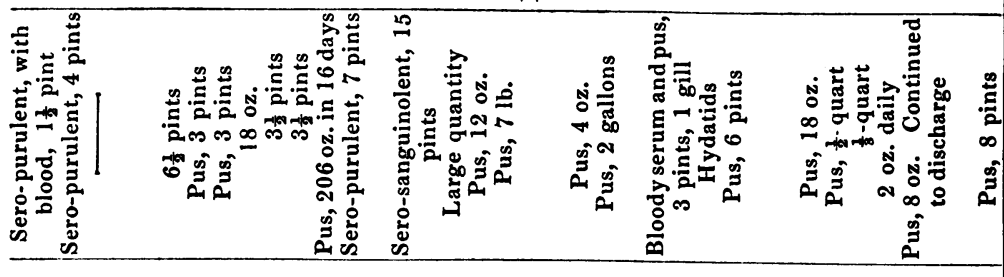

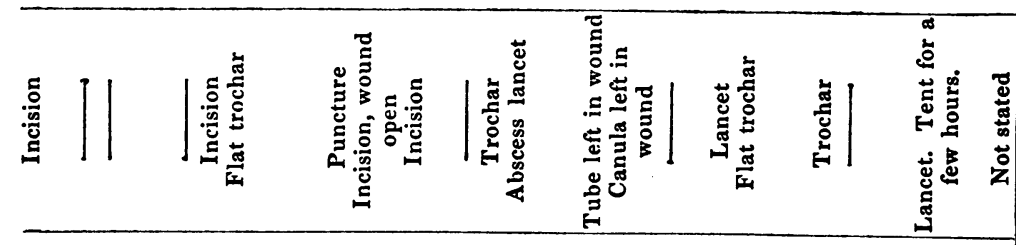

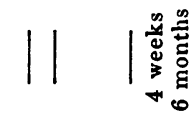

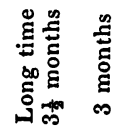

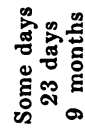

常|

幽峦

है

हี่

$1+3$

เล ลิ

๙

2

สี

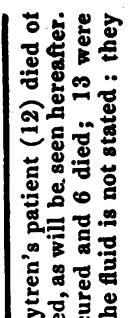

a...

5.

$\sum \mathrm{g} \pm$

这

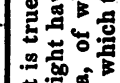


Encouraged by the number of recoveries exhibited in the foregoing Table, and believing that many persons might be saved by paracentesis thoracis who were almost sure to die unless it were performed, I tapped all the cases of empyema and hydrothorax which fell under my care, in which the means adopted for the cure of these diseases did not after a few weeks produce a sensible diminution of the effused fluid, and found the success attendant upon this practice to exceed my most sanguine expectations. Several of my friends adopted this mode of treating similar cases with equal success; and I am now prepared to lay before the Society twenty-four cases, the whole number which has come within my immediate knowledge since the year 1833, in which tapping the chest was performed, and to show from them that this operation is as free from danger as any other which is performed on the human body, that most of the evil consequences supposed to attend it are more imaginary than real, that it is generally successful when employed at an early stage of the diseases under consideration, and that the chief cause of its failure is its being postponed until too late a period. But, before I lay these cases before the Society, I beg to make a few observations in reply to the principal arguments usually brought forward against the operation. Those which have already been mentioned can scarcely be said to require any serious refutation, for every day's experience shows that the absorbents fail to remove a large quantity of effused fluid from serous cavities, and yet effectu- 
ally prevent its re-accumulation. Not a single case can, I believe, be found on record in which the operation proved dangerous, except when it was performed upon the healthy side, and the Tables contained in this paper, as well as the reports given by Sprengel, clearly prove that a large majority of the patients upon whom paracentesis has been performed have recovered.

It is also objected to tapping, that it frequently induces dangerous syncope; that it is of little use in peritoneal effusions, and therefore from analogy cannot avail more in effusions into the pleura ; and that, as it does not cure the inflammation which causes the morbid and excessive secretion, no object is attained by merely removing the fluid. To these arguments I reply, that in none of the cases recorded in this paper did the abstraction of several pints of fluid at one time induce even a tendency to syncope; that paracentesis often cures peritoneal effusions, and therefore from analogy we may expect it to be equally successful in pleuritic effusions; and, that tapping is not recommended for the removal of the fluid until after the inflammation has been subdued by other means.

But there are other arguments, which constitute in the minds of many practitioners very strong objections to the operation; and which therefore require to be noticed. For example, it is said that the admission of air during the operation is attended with danger, and frequently renders it unsuccessful.

This objection derives its importance from the high character of the men by whom it is held, and would, if it were well founded, constitute a very strong argu- 
ment indeed against tapping the chest, because it is impossible without the assistance of some valvular apparatus to prevent the ingress of air during the operation, inasmuch as the patient begins to cough very violently as soon as a certain quantity of fluid has been withdrawn, and his rapid and forced inspirations cause the air to rush through the canula into the chest, however watchful the operator may be to prevent it. But it appears difficult to me to conceive what peculiar cases could have induced belief in such a source of danger; for in every case which has fallen under my observation a considerable quantity of air entered into the pleura during the operation, and in some of them so freely as to excite all the physical signs of pneumothorax, but in none of them did it produce any permanently evil effect, a few hours being sufficient for its spontaneous removal : in one instance only did it cause even temporary inconvenience. Now when it is considered that out of twenty-four cases, nine of which were instances of purulent effusion, in which $a$ fortiori the deleterious action of air ought to have been especially manifested, no mischief followed, it appears but fair to presume that this danger has been much exaggerated. The supposition that the action of the air may militate against the recovery of the patient by its pressure upon the lung, appears to carry with it, as an argument against paracentesis, its own refutation : for no greater pressure can be exerted by the air which is admitted during the operation than had been previously caused by the accumulated fluid; 
and as the former can only interfere with the expansion of the lung during the time required for its absorption, and the experiments of Speiss * have fully proved that air introduced into the pleura is invariably removed in a few days, it follows that its admission must be less adverse to the recovery of the patient than the continued pressure of the fluid during the longer period which it would be likely to remain unabsorbed. In those very rare cases in which the air admitted during the operation is not speedily absorbed, but produces dyspnœea, it is very easy to pump it out with an ordinary syringe, and thus put an end to the mischief. This was done for Silas Hann, $\uparrow$ the only one I ever met with where the air did not in a short time disappear spontaneously from the pleuræ.

The last objection I shall notice is, that the operation is unnecessary : this is one which must be made by all those who hold or adopt the opinion advanced in a posthumous essay of the late Dr. Hope, viz. that all cases of empyema really curable, are curable without paracentesis. $\ddagger$ This conclusion appears to have been drawn from the results of thirty-five cases of that disease, recorded in the paper just alluded to, in which the exhibition of mercury, continued until the patients had been brought completely under its influence, was followed by the removal of the fluid. Now without calling in question the existence of empyema in

\footnotetext{
* De vulneribus pectoris penetrantibus.

† Appendix, Case 2.

‡ Vide Medico-Chirurgical Review, 1842.
} 
all these cases, or seeking for the proofs of its presence, I would ask, before I proceed to combat the objection, what is meant by the cure of empyema? If it be the simple removal of the fluid, I am not inclined to dispute the possibility of effecting so much by the power of mercury, for I have had many cases in which the symptoms of fluid in the chest have disappeared under its action; but this is not necessarily a cure; for the lung which has been compressed by the fluid is often left so altered in its structure, that it never again can perform its healthy function. But if it be meant, that in all curable cases of empyema, mercury, exhibited in the manner prescribed, will not only cause the absorption of the fluid, but the restoration of the lung to heaith, the experience I have had of the effect of that medicine in this disease, precludes me from subscribing to this assertion. I have had many cases in which it has failed to cause even the absorption of the fluid, and very many in which after effecting its removal, it left the lung in a condition very different from that of health; in a majority of the cases recorded in this paper, mercury had been freely exhibited before the patients came under my care; in several it was given by my own direction; in three, ptyalism was produced and kept up, but nevertheless the fluid was not absorbed. To justify the assertion that all curable cases of empyema may be cured by mercury, without paracentesis, or, in other words, that no case of empyema which cannot be cured by mer- 
cury is curable by the operation in question, it would not be sufficient to show that paracentesis had not succeeded in curing any case where mercury had failed, unless it were also shown that at the time of its performance no such changes had taken place in any of the thoracic viscera, as rendered a cure impossible. Indeed, I am unable to conceive how such an assertion could be proved, for even if the whole of those thirty-five cases were perfectly cured, that is, not only that the fluid was removed, but that the lungs were restored to health and soundness-which is not alleged to have been the case-the point asserted would even then be rendered probable only, because other cases might still occur, in which mercury would fail ; but it is not stated that these cases were so perfectly cured, and in the absence of evidence, or even any statement to that effect, we can only receive this assertion as the expression of the opinion of the late Dr. Hope,* an opinion which we know to be contravened by the reports of many of the cases which have been published as cured. They state, that the shoulder of the affected side had dropped, that the chest was left contracted, and that the spine was deformed; facts which clearly indicate an accommodation of the bony parietes to a diminution in the size of the lungs, and lead us to the inevitable conclusion, that the lungs so far from being cured, were too much injured to expand to their former dimensions. 
I have lately met with two striking examples of the extent of mischief sometimes done to the lungs of patients said to be cured of effusions into the chest by absorption. Elizabeth Leighton, æt. 37, was admitted into the Hospital for Diseases of the Chest, on 30th January 1843; the left side of her chest was much flattened, being dull on percussion, and without even the feeblest sound of respiration. She said she had been in the Westminster Hospital some years before, suffering from an attack of pleurisy, of which she had been cured. Supposing that there must be fluid in the left pleura, I introduced the grooved needle, but found none. She died on the 27th of June, and on examining the body the left lung was found considerably diminished in size, impervious to air, condensed into a dry homogeneous mass, and retained in contact with the ribs by a thickened and almost cartilaginous pleura : no tubercles were found in either lung.

Douglas Graham, æt. 53, was admitted into the same hospital, March 2nd, 1843. The right side of his chest was nearly motionless, and very dull on percussion every where; no vesicular respiration could be heard in it; a sort of creaking leathery sound was audible at each inspiration, but air could not be perceived entering the lung any where, except under the clavicle, and there, it was accompanied by loud and large mucous crepitation : something like pectoriloquy was heard in this part; he could not remember having had pains of either side. He died on the 8th of October, 1843. 
Sectio cadaveris.-Body much emaciated. On opening the thorax the upper third only of the right lung could be seen; the lower two-thirds were adherent to the ribs, condensed into a dry mass ; the pleura was much thickened; there was a cavity at its upper part, and purulent infiltration into the lung; the left lung was somewhat emphysematous, and contained some miliary tubercles.

These cases $I$ fear are more common than it is generally supposed: they show that patients may be sent out of an hospital, apparently cured of empyema and hydrothorax, because the fluid has been absorbed, but who must suffer all their lives from the loss of one lung, and they prove most clearly that absorption of effused fluid is not necessarily a cure.

From the zeal manifested by Dr. Hope, as well as by many others of the profession, to remove fluid from the chest by any other means rather than by tapping, we might be led to imagine that this must be either a very painful or a very injurious mode of treatment, and that any other would be better for the patient ; but a moment's consideration of his condition, when an operation is thought of as a curative measure, will convince us that the contrary is the case. Until the remedies usually employed in such cases have subdued the pleurisy, but have failed to remove the effusion to which it has given rise, no one ever thinks of having recourse to an operation; mercury is the remedy which is always administered;

vol. XXVII. 
our patient is already salivated; his chest is full of fluid, and his strength is prostrated at the very time when we are called upon to decide, whether it is better for him to suffer all the miseries of a protracted salivation, or to be tapped. The very fact that the powerful remedies already employed have not very much diminished the effusion, proves that his constitution is scrofulous, and therefore one upon which mercury is known to act as a poison. If we persevere in the use of that medicine, we are certain that we shall do mischief, and we are by no means certain that we shall succeed in getting rid of the fluid by absorption, as some of the cases in this paper prove; but even if we could be sure of doing so, it is a slow and tardy process, and during the period required for its accomplishment, time is allowed for some of those irremediable changes of structure to take place in the lungs, which are noticed in the report of almost every fatal case of empyema or hydrothorax, and which must render its restoration to its healthy size and condition impossible, for, it appears certain that a large quantity of fluid of any kind cannot remain more than a certain length of time in the cavity of the pleura, without carnifying the lung, and for ever depriving it of its expansibility. Changes nearly as unfavourable to recovery happen to the pleura. It almost always becomes thickened, and sometimes cartilaginous, and so changed from its original structure, that it is incapable of resuming its healthy action, and must continue to secrete fluid; besides which, 
bands are formed between the membranes, which lead to future contractions of the chest. The cure of such cases, if cure it can be called, must be, as we have above seen, attended with great deformity, contraction of the chest, and the partial, if not total loss of one lung. It is moreover manifest, that absorption in empyema introduces into the circulation, matter which is totally unfit for the support of the body, and is, besides, by no means innocuous; and though the same objection cannot be made to the absorption of serum, nevertheless the very fact of its remaining any great length of time after inflammation of the pleura has been subdued, affords strong grounds for believing that it will not be absorbed. The retention of pus, possibly of serum, for a long time in the pleura, leads to the development of tubercles in the lung of the opposite or even of the affected side. This has been pointed out by Broussais, and Dr. C. J. B. Williams,* and a confirmation of it may be seen in the cases of Dyson and Spader ; $\nmid$ we have, therefore, to apprehend, not only that the lung which is suffering from compression may lose its power of expansion, if we wait the length of time which the process of absorption usually occupies, but that a new and more fatal disease may assail the opposite organ.

In addition to the effects which the long continuance of pleuritic effusions produce upon the heart, lungs, and other organs, there are some which are

* Vide Library of Medicine, art. Empyema.

$\uparrow$ Vide Appendix, Nos. 4 and 15. 
felt by the constitution. The history of the more chronic forms of empyema and hydrothorax shows that, after a certain period, the powers of the patient begin to fail, debility and emaciation commence, and proceed rapidly. Hectic fever soon follows, colliquative sweats consume the little strength which is left, and the patient's powers and energies become completely prostrated. For these and other less important reasons, which I should enter into here, were it. not for the necessity I am under of curtailing this paper, I am persuaded that the attempt to effect the absorption of fluid from the chest, under such circumstances as I have above detailed, inflicts much more injury upon a patient than tapping.

There are some highly respectable medical men, who admit that paracentesis is necessary in empyema, but maintain that it is wholly unnecessary in hydrothorax, because those cases of the latter which cannot be subdued by antiphlogistic means, may be cured by generous diet, with the use of iron and tonics. I admit that many cases may be so cured, for some such have fallen under my own observation, but I have met with many others in which such treatment has totally failed. I must, therefore, maintain that the greater number of the arguments already brought forward against trusting to absorption, are applicable equally to both these diseases ; but the proof that tapping is not unnecessary in the latter, is directly to be inferred from the fact that many die daily of it. Dr. Boyd, in his Vital Statistics, states, that in the space of three 
years, in one institution, the St. Marylebone Infirmary, he opened the bodies of twenty-four persons who died of hydrothorax, and of twelve others, in each of whom he found evidences of pleurisy and effusion.* Now, I have too high an opinion of the medical skill of the gentlemen who had the charge of these patients, to doubt that all the usual means were adopted in their treatment. I am aware that tapping was not employed, and therefore it is plain that for the former, viz., the twenty-four cases, at all events that mode of treatment was not unnecessary.

Now, the objections to paracentesis are reduced to this-that it inflicts a wound; whilst in favour of it, it may be said, that in empyema it at once removes a noxious fluid, and does far less injury to the constitution than the absorption of purulent matter; that in both empyema and hydrothorax, it immediately relieves the lungs from the effects of pressure, and accomplishes that which internal medicines cannot, in the majority of cases, effect in weeks; and by its early employment, those irremediable changes already noticed are anticipated, and every chance is afforded for the complete restoration of the lung; that it removes that distension of the pleura, which paralyses the absorbents, and if inflammation be overcome by suitable remedies, it will effectually cure these diseases, provided the lungs are sound, and that, without inducing any evil consequences. It is, as Dr. Townsend observes,

* Vide Edinburgh Medical and Surgical Journal, No. 156. 
" an operation at all times easy of execution, productive of little pain to the patient, generally followed by immediate relief, and has, in numerous instances, been crowned with complete success."* It has been recommended by many eminent physicians and surgeons on the continent, in America, and in our own country-viz., Baron Larrey, J. P. Frank, Bell, Dr. Elliotson, Dr. Forbes, Dr. Copland, Dr. C. J. B. Williams, Dr. E. Harrison, the late Dr. Davis, and several others.

Having now replied, I hope satisfactorily, to the principal objections usually made against paracentesis as a curative measure in effusions into the pleura, it remains for me to lay before the Society my reasons for believing that that operation constitutes in many cases an important part of the treatment of these affections; but, to prevent any erroneous idea as to the nature of the cases for the cure of which I have ventured to recommend it, I beg to observe that in this paper the name of empyema is given to those only in which the fluid is purulent, and that of hydrothorax is used as a generic one, comprehending under it two speciesinflammatory hydrothorax, in which serous effusion has succeeded to inflammation of the pleura; and mechanical hydrothorax, in which the effusion is symptomatic of organic disease in other structures.

Indications for the Operation.-Paracentesis is indicated to us as a remedy for those cases of empyema which do not quickly yield to ordinary

* Vide Cyclopædia of Practical Medicine, art. Empyema, p. 42. 
treatment by the mode which nature often adopts for evacuating the fluid. Ulceration commencing in some portion of the pleura, extends through the adjoining structures, and makes an outlet for the accumulated fluid either through one of the intercostal spaces, or through the lung itself into a bronchial tube. The removal of the fluid is shown to be an indispensable part of the treatment of empyema by the manner in which a cure is effected in this disease. As the pus flows out, the upper portions of the pleura, which are first emptied, come into contact and adhere ; the adhesion gradually extends downwards till the two layers of membrane become perfectly agglutinated together; no further accumulation can then take place, and the cure is effected by the obliteration of the cavity. Case 8 in the Appendix, for which $I$ am indebted to Dr. Anthony Todd Thompson, affords a good illustration of the manner in which pus is discharged through an intercostal space, and a cure frequently effected. The subjoined case appears to have been one in which the opening was made between the cavity of the pleura and a bronchial tube.

Caroline Holloway, æt. 19, a scrofulous looking girl, after suffering a few days from pain in the upper part of the left side of her chest, but not so much as to oblige her to desist from her employment as a still-room maid, was suddenly attacked with an alarming sense of suffocation, which obliged her to jump up in bed, when she brought up in a stream so large a quantity of foetid pus that it was received 
in a wash-hand basin; these symptoms recurred in paroxysms frequently afterwards, and were always relieved after the discharge of foetid matter; the quantity brought up the first day measured more than three pints; that which came up daily for a week afterwards exceeded a pint. Her left side was every where very dull on percussion, no sound of respiration could be perceived in it any where, except at the root of the lung; the voice did not produce the ordinary vibration, but ægophony was well marked under the posterior and inferior angle of the scapula ; neither " bourdonnement amphorique" nor " tintement metallique" could be perceived. I had little doubt from comparing all the signs, that the girl was suffering from empyema; but as there was some obscurity in the case, I requested the assistance of Dr. Edwin Harrison. He detected the same physical signs, and agreed with me as to the probable nature of the case. Neither of us could account for the large quantity of pus which was brought up daily, except on the supposition that a communication existed between a bronchial tube and the cavity of the pleura filled with pus, and yet the symptoms indicative of the presence of air were wanting in this case. I proposed to her master, that she should be tapped, but he would not consent to its being done, fearing she might die after the operation. Finding the patient daily becoming worse, I resolved, as a "ressort dernier," to have as many cupping glasses as possible applied over the left side of the chest, but to have only 
10 ounces of blood abstracted. After the operation I gave her a full dose of opium. Next day the expectoration had diminished to about 4 ounces; her breathing was very much relieved, and she felt better. From this time she gradually improved, respiration returning, and the dullness of the chest disappearing, and in three weeks she was well enough to go to her mother's house. Some months afterwards I had an opportunity of examining her chest : respiration was distinctly audible, in the side which had been affected; the sound on percussion was nearly natural, and scarcely a trace existed of the formidable disease under which she had laboured.* The efforts of nature to evacuate pus out of the pleura are so very frequent, as the records of cases of empyema clearly show, that they suggest to us the propriety of effecting promptly by an operation, that which is slowly done by the ulcerative process, provided the operation occasion no danger to the patient.

Paracentesis is not pointed out to us as a remedy for hydrothorax, by any effort made by nature to get rid of serum, but it is so by the effects which the pressure of fluid produces on the thoracic viscera. The cure of this complaint is not effected, as

* This case at first sight appears to afford an argument against the necessity of paracentesis, inasmuch as the patient recovered and the lung became respirable without it, but the cavity of the pleura was virtually tapped and the pus was evacuated through an outlet of nature's making, and the cure was then effected by the adhesion of the membranes; such a termination is so rare that we cannot calculate upon its occurrence. 
in empyema, by the adhesion of the pleuræ, but by the restoration of these membranes to a state of health; our object in operating, therefore, is not to remove the obstacle to the pleuræ coming into contact, but to prevent, or put a stop to those organic changes which the effusion is producing.

Cases in which the Operation should be performed. -It would be desirable to ascertain if possible the cases for which paracentesis is the most appropriate remedy.

- For serous effusions, which proceed so rapidly that the life of a patient is threatened by its speedy accumulation, it is admitted to be the only remedy. M. Lichtenstadt, Professor at St. Petersburgh, relates an instance of this kind, in which the life of a child was lost, from the operation not having been speedily employed.

For empyema, it ought always to be performed the moment the nature of the case is ascertained.

For serous effusions occurring in persons of scrofulous habits or very delicate health after pleuritic attacks, for the cure of which the necessary treatment has either failed, or been neglected, paracentesis will generally be required, for the usual remedies seldom produce any considerable diminution of the fluid.

In mechanical hydrothorax, paracentesis can only be recommended for the purpose of relieving the difficulty of breathing caused by the pressure of fluid upon the lung, and of prolonging life; it cannot cure this disease, for this form of effusion 
depends on a morbid and irremediable condition of the heart, which obstructs the free ingress of blood from the pulmonary and pleural veins, and thus causes an exudation of serum into the cavity of the pleura. After the evacuation of the fluid, however, it appears in many cases possible, to keep the quantity of blood in circulation in such proportion to the size of the obstructed opening in the heart, that distension is prevented, and no further effusion takes place for some time: therefore, though the operation cannot be advised as a curative measure, it sometimes does so much good as to warrant its being proposed to a patient suffering under this form of hydrothorax, as one sure to afford immediate relief, and which holds out a hope of prolonging his life for some weeks or even months, leaving it to him to decide whether he considers it worth while to undergo it for the sake of such a result. Life was certainly prolonged seven months by the operation in Bray's case.*

Conditions of success.-Whether the operation shall materially assist in curing cases of simple pleuritic'effusion, or afford merely temporary relief, depends on the time at which it is performed. To be successful, it is indispensably necessary that it should be employed before either the constitutional powers of the patient are too much reduced, or the thoracic viscera have undergone irremediable organic changes : for in the former case the absorbents cease to perform their functions, and therefore cannot pre-

*Vide Appendix, No. 3. 
vent the re-accumulation of fluid after it has been removed; in the latter, a perfect cure is impossible. It is only when the lung is in a condition to expand to its full size, according as the pressure upon it is withdrawn, that the cure is effected without any visible alteration of shape in the diseased side. But when the operation is delayed till the lung has become atrophied, condensed, bound down by adhesions, or in any other way prevented from at once expanding sufficiently to meet the ribs, the shoulder becomes depressed and the side contracted, in order to bring the pleuræ into contact with each other : the body is then deformed, and the original capacity of the lung is very much diminished. When the lung is so much reduced in size that the pleura investing it cannot be brought into contact with the costal pleura, a cure is impossible: for a space must intervene between them, into which pus or serum will continue to be secreted, and the operation will be required again and again, till the patient dies from exhaustion. Under such circumstances, paracentesis cannot be looked upon as a curative measure, and therefore should only be employed to relieve distress of breathing. The opinion of Laennec was decidedly in favour of operating early.* Mr. Youatt, in his lectures on pleurisy in the horse, inculcates the necessity of having recourse to the operation as soon as it is certain that there is a considerable quantity of fluid in the chest.

In depending mainly for its success upon its being

* Vide Dr. Forbes' translation of Laennec, page 191. 
performed as speedily as possible after the necessity for it has arisen, this operation is not singular. Releasing a strangulated hernia is often unsuccessful, simply because it has been too long deferred. Laryngotomy always fails if the brain has previously become affected by the circulation of imperfectly arterialized blood. In like manner, paracentesis thoracis is sure not to succeed if it be deferred too long. The judgment of a large portion of the profession must necessarily, in the absence of personal experience, be much influenced by the opinions of men of high standing; and as some of them are opposed to paracentesis, and none of them recommend it as a curative measure, it is not surprising that it should have fallen, as it has done, into very general disrepute, and been employed merely to afford temporary relief. Such being the usual practice, the fatal results which usually follow the operation confirm the prejudices which so generally prevail against it, and prevent us from being surprised at its having fallen far below that rank in the list of remedies to which its merits fairly entitle it.

Time for the Operation.-It would be very desirable to fix, if it were possible, the precise period after which the operation ought not to be delayed. That evidently should be a little before those organic changes, so often alluded to, are on the point of becoming irremediable; but that point of time is not easily discovered. Indeed, the stage of the disease at which an operation will anticipate those changes, can only be determined by our knowledge 
of the earliest date, after effusion has taken place, at which they have ever prevented paracentesis from being so completely successful as to leave the lung expanded to its full size, after the removal of the fluid. That earliest date I believe to be about three weeks; and if I were myself the subject of empyema, or hydrothorax, I should not wish the operation to be deferred to any later period. Indeed I can see no good reason for wishing to postpone the operation as long as possible. It is a perfectly safe one, and the pain is very trifling: it is therefore better for a patient that it should be performed too soon, or even unnecessarily, than that he should be exposed to the risk of having his disease rendered incurable by delay.

I confess my opinion to be, that as soon as it is clear that pleurisy is subdued, and that a large quantity of fluid remains in the chest, we should proceed at once to ascertain its quality, by introducing the exploring needle (invented I believe by Sir B. Brodie), and if it is found to be purulent, the operation should forthwith be performed, because it is very far from being desirable that pus should be absorbed into the circulation, or prevent by its presence the adhesion of the pleuræ. If it is found to be serous, we may wait till the end of the third week, to see if medicine will cause absorption to proceed rapidly; and if it does not, the operation should not be deferred.

Many cases are recorded of patients who had been tapped with what is termed complete success, after having laboured under pleuritic effusions for several months; but I believe it would be found that 
in these cases the lungs never expanded to their original dimensions. No case occurred in my practice in which, after the lapse of five or six weeks from the commencement of the effusion, a patient was perfectly cured. The changes produced in the lung after this period, and sometimes before it, were irremediable: the fluid, after having been drawn off, accumulated again, and the patient either sunk, or survived with a considerable loss of lung. Case 16 in the Appendix is an instance of this kind : the patient recovered, but no vesicular respiration was perceived in the affected lung, and his death afforded an opportunity of seeing the condition to which it had been reduced.

The Operation.-Some difference of opinion exists as to the manner in which the operation should be performed, and the quantity of fluid which should be evacuated at one time. Formerly an incision was made into one of the intercostal spaces, the fluid was evacuated at once, and the wound was left open. Dupuytren, I believe, used to operate in this manner. More recently, the opening in the pleura has been made with a trochar, and either a catheter left in the wound, by which the fluid is drawn off gradually, the opening is made fistulous, or the wound is closed immediately. The two former modes appear to me objectionable, because they allow an almost continued ingress and egress of air, which $I$ believe to be sometimes highly injurious; for although, as I have before observed, the entrance of air during the operation is not productive of any bad effect, yet 
its continued admission appears to excite an inflammatory state of the pleura.

Dr. Stroud published a case in the Medical Quarterly Review for October 1833, the principal features of which were, that after tapping the chest of a lad, a gum elastic catheter was left in the wound; that the fluid first drawn off was clear serum, but that which was discharged afterwards became daily more like pus, until the tenth day after the operation, when it was "yellow pus."

Dr. Stroud, commenting on this case, writes thus-" It is more probable that the gum elastic catheter retained in the pleural sac, and replaced when it occasionally escaped, or else atmospheric air, which during inspiration could scarcely fail to be sometimes admitted through the external aperture, was the cause of that increased and morbid action, to which the formation of pus must ultimately be ascribed."*

In many of the cases reported in the Table already given, the wound was left open, and the fluid was allowed to evacuate itself daily, without producing (to all appearance) any evil consequences ; we cannot, therefore, believe that this mode of operating is necessarily injurious: the objection to it, however, seems to be, that it has no advantages sufficient to compensate for any risk, however small that may be. In cases of pneumothorax, it may be desirable to keep up an opening; but in simple empyema or hydrothorax, it is useless to allow the fluid to drain

* Vide Medical Quarterly Review, vol. i. 
off, and therefore, in these diseases, the only motive for doing so is, to avoid the necessity of a second operation. Now, the operation itself is so very little more painful than common bleeding, that it is not worth incurring the smallest risk to avoid it. In almost all the cases recorded in this paper, the operation was performed with a common trochar, the whole of the fluid was evacuated, and the wound was closed immediately with adhesive plaister; and if the fluid accumulated again, the operation was performed as before, without a single instance of any evil consequences from it. As to the quantity of fluid to be removed at one time, the results of twenty-four cases have shown that there is no danger in emptying the pleura. It is clear, that if we evacuate more fluid than can be replaced by the expanding lung, air must fill the vacuum; but as this does not seem to be attended with either danger or inconvenience, $I$ think it better to evacuate the whole of the fluid at once with a trochar.

The part of the chest in which the opening should be made, has been pointed out clearly by Laennec.* He recommends the space between the fifth and sixth ribs, counting from above downwards, and a little behind the digitations of the serratus major, as being the most dependent point in the horizontal position, freest from adhesions, and the seat of the largest quantity of fluid. It is in this situation that the operation was performed in almost all the cases I have to bring before the Society. A small but

$$
\text { * Op. cit. }
$$

VOL. XXVII. 
deep incision was made, a little below the middle of an intercostal space, the skin being previously drawn upwards or downwards, so as to render the opening somewhat valvular; a sharp trochar and canula were then passed inwards, and slightly upwards, with sufficient force to puncture the pleura. In some of the cases recorded in this paper, the pleura was pushed before the trochar, and not perforated in the first instance, owing either to thickened condition of the pleura, or the bluntness of the instrument. After the operation, care was taken to restore the pleura to a healthy state; the slightest return of pleuritic pain, the accession of febrile action, or dyspnœea, was immediately combatted, by either dry cupping extensively over the affected side, ordinary cupping, or counter-irritation, aided by the internal administration of small doses of mercury, and a well-regulated diet; when the patient appeared debilitated, a generous diet was given, with iron and quinine.

On the Diagnosis. - In conclusion, I beg to notice a few diagnostic signs, which were observed in several of the cases $I$ have reported, and for some of which I am indebted to Dr. Frederick Bird, a gentleman whose talents and zeal cannot fail to raise him to a high rank in his profession, and who at the time this paper was drawn up, was our clinical clerk in the Westminster Hospital.

The physical signs of effusion commonly laid down are readily recognized, even by an inexperienced auscultator, when the quantity of fluid is 
considerable, but no little difficulty is sometimes felt in detecting its presence, when the quantity is small. It may be overlooked from the following causes : the fluid, as a matter of course, gravitates to the most depending part of the chest, and if percussion elicits a dull sound in that situation, on the right side, it will be a question whether that sound is owing to the presence of fluid or to the liver; if, on the left side, a clear sound is elicited, it by no means follows that fluid is not present, for the clear sound may be accounted for by the inflated stomach lying behind a small quantity of fluid. In the former case, I have been greatly assisted in my diagnosis by the rules communicated to me by $\mathrm{Dr}$. Edwin Harrison, for determining the height of the liver, and in the latter case by the mode of percussion suggested by him, by Dr. Addison, and by Dr. C. J. B. Williams. They most correctly point out, that very gentle percussion will elicit the dull sound depending on the presence of fluid, without producing any sound from the tympanitic stomach. In addition to the dullness on percussion, as a sign of the presence of fluid, we have a very valuable indication afforded by the absence of the vibratory thrill produced by the voice, and which is readily detected on the healthy side. This is one of the most simple and valuable evidences of pleuritic effusion.

In the ocular examination of the chest, the inaction of the intercostal muscles, their smoothness or protrusion, and the general enlargement of the affected side, with (in the later stages of the disorder) the de-

Q 2 
pressed shoulder, are all well-known important diagnostic signs: but there is another, of equal value, which I believe has not been hitherto described. It consists, in a marked degree, of fullness, or even protrusion, of the infra-clavicular region on the affected side; this often exists to a remarkable degree, and it is generally associated with increased resonance of the voice in the same situation. Dr. F. Bird observed it in all those cases which have recently come under our observation. The bulging of the intercostal muscles has been regarded as a valuable indication of the presence of a large quantity of fluid. Dr. C. J. B. Williams has particularly alluded to this sign, in a clinical lecture published a short time ago, in which he remarks, " that when a large accumulation has taken place, the side becomes permanently expanded, and the intercostal spaces are effaced." My own experience does not allow me to regard it as a constant or a frequent sign; and I fully accord with Dr. Stokes, who is of opinion, that the protrusion of the intercostals only takes place in cases of purulent secretion; and the truth of this observation has been illustrated in several cases recorded by himself, as well as in several contained in this paper. The remark of an old writer, Albertini, appears not to be without truth, "that it is to the irritating action of the secretion, and not to its quantity, that the production of the effect just alluded to is attributable." Certain it is, that cases constantly occur, in which serum has been effused in very large quanti- 
ties, sufficient to displace the heart, and to exert considerable pressure on the lung of the opposite side, without producing any bulging of the intercostals, - a fact which may be accounted for by the altered position of the mediastinum; nor. is it less certain, that in cases in which a comparatively small quantity of pus has been formed, the intercostals have been much protruded. That this protrusion does not depend on the mechanical pressure of the fluid alone, is clear from the cases already alluded to, in which the protrusion was not in proportion to the quantity of fluid contained in the pleural cavity. In the case of Spader, ${ }^{*} 105 \mathrm{oz}$. of serum were found in his chest, with an apparent retraction of the intercostal muscles of the affected side, whilst in the case of Rodwell, $\uparrow$ in which the fluid was smaller in quantity, but purulent, the intercostals were remarkably prominent, although the effusion in the former case had existed for a much longer period than it had done in the latter. But a still more satisfactory illustration is afforded in the case of the patient, Sampson Glover, $\neq$ in whom the absence of this sign, in an early period of the disease, and its subsequent development in a later one, marked the transition of the serous to the purulent secretion. When paracentesis was first performed, $75 \mathrm{oz}$. of serum were drawn off, the intercostal muscles not being at all prominent; whereas,

\footnotetext{
* Vide Appendix, No. 16.

+ Vide Appendix, No. 22.

$\ddagger$ Vide Appendix, No. 15.
} 
shortly before his death, they had been considerably protruded, and on dissection it was discovered that the contents of the pleura had assumed a purulent character; other equally satisfactory examples are afforded in the Table.

Experience, then, appears to show, that the protrusion of the intercostals is to be regarded as indicative of the quality, but not of the quantity, of the effusion.

The position assumed by the patient has been regarded as a valuable indication of the side on which the disease exists; the patient generally lying upon the back, or occasionally on the diseased side, but being unable, from increased dyspnœa, to remain even a short time upon the unaffected side: this is usually attributed to mechanical causes, viz. the pressure of the fluid upon the heart and opposite lung, and the displacement of the abdominal viscera; whatever the cause may be, in a practical point of view, it is necessary to observe, that although the decubitus alluded to is a frequent indication, yet it is by no means a constant one; many recorded cases have sufficiently illustrated the dangerous fallacy attending it. Dr. Townsend refers to one case in which the death of the patient was produced by paracentesis having been performed on the healthy side, the operation having been guided chiefly by the position of the patient. Many of the cases recorded by Morgagni,* on the authority of Valsalva, are those in which the patient was quite unable to lie

\footnotetext{
* De sedibus et causis Morborum.
} 
upon the diseased side, and more than one similar instance is met with in the accompanying cases; the exceptions indeed are so numerous that this sign becomes of less than secondary value. The ability to lie on the healthy side has been theoretically explained by Dr. Townsend, who imagines that pleuritic adhesions having formed, prevent the gravitation of the fluid; but in the cases given by Morgagni no such adhesions existed, and it is probable that the cause is to be sought for in the healthy condition of the lung of the opposite side, and in the fact of the patient having become gradually habituated to the effects of the disease.

The frequent occurrence of pleuritic effusion upon the left side of the chest is remarkable; the ratio in the cases contained in this paper being as seven to five, whilst those recorded by Valsalva and others contained in the "Sepulchretum" of Bonetus afford the same result. This, remarkable as it is, can only be offered as a fact unsupported by any explanatory hypothesis, the cause remaining in the same obscurity as that which determines the early development of tubercles at the apices of the lungs.

For the purpose of presenting in a condensed form the general results of the cases in which paracentesis has been employed under my own observation, or that of my friends, I have, in the subjoined Table, inserted in separate columns the most material features of each of them. 


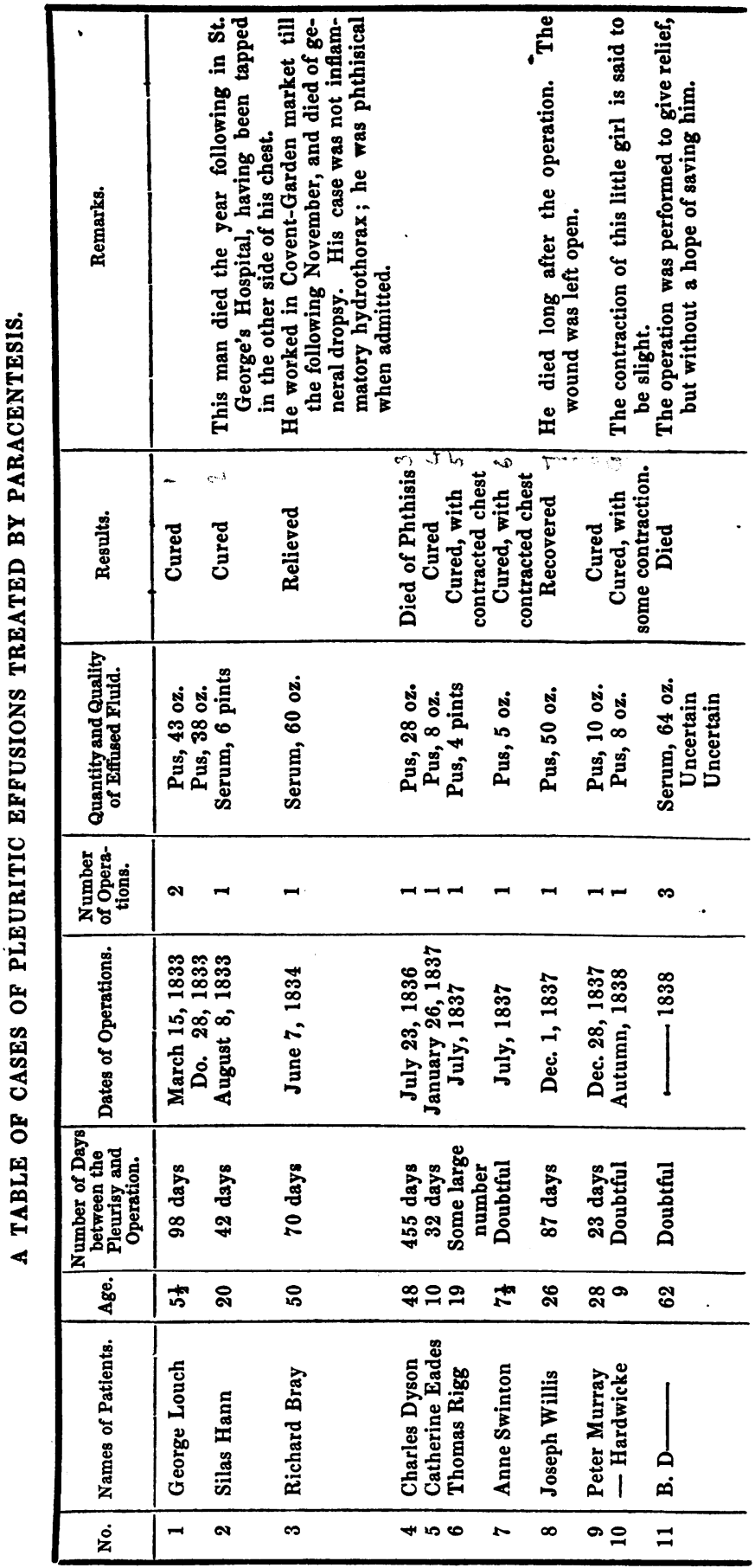




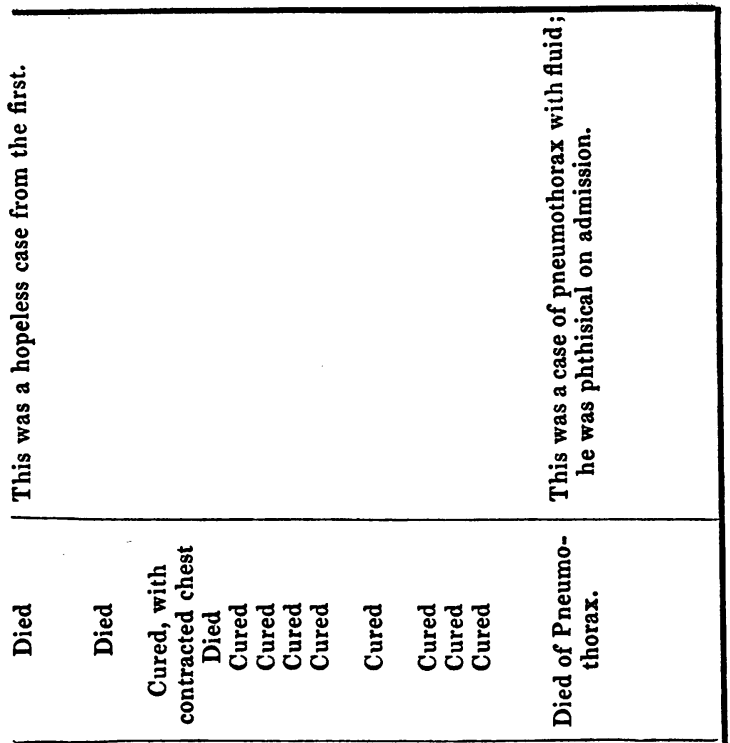

ํํㅇ

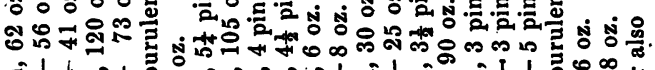

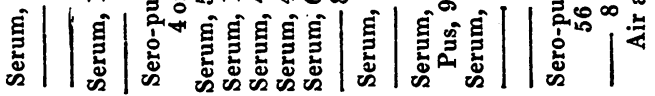

粱

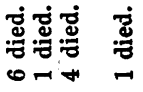

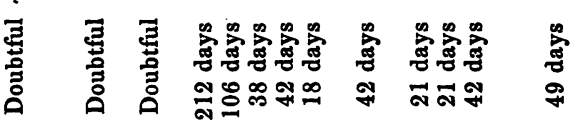

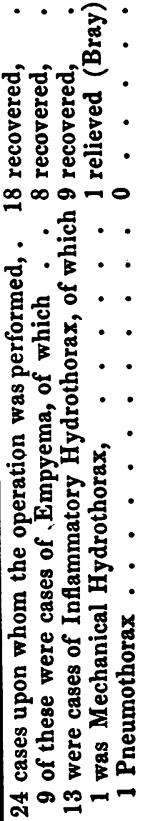

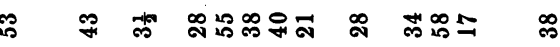

\begin{tabular}{|c|c|c|c|c|c|}
\hline $\begin{array}{l}\frac{1}{2} \\
0\end{array}$ & 1 & 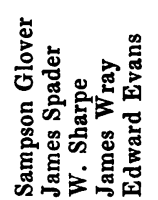 & 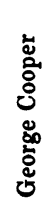 & 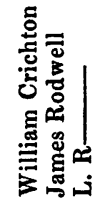 & 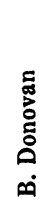 \\
\hline$\cong$ & \pm & $20=\infty$ & 오 & ลีส ส & N゙ \\
\hline
\end{tabular}


Mr. Benjamin Phillips has favoured me with the following memorandum : "Among my notes of the result of this operation I find a record of 122 cases, of which 88 were cured. I find particularized 31 cases of pyothorax, of which 26 were cured, and 9 cases of hydrothorax, of which 6 were cured."

I am not acquainted with the particulars of these cases.

From the perusal of the foregoing Table it will appear evident that I have not made any over-statement in saying, "that this operation is not more dangerous than any other which is performed upon the human body, and that the evil consequences supposed to attend it are imaginary rather than real, inasmuch as it not only was not fatal in one of these twenty-four cases, but did not cause in any of them the smallest permanent inconvenience. In every instance where it was employed at an early stage of empyema, or inflammatory hydrothorax, it was successful, and failed to cure in those only where it had been long deferred. The total mortality proportional to the whole number of cases, viz. six in twenty-four, is less than that which occurs after most operations, and yet it is more than can fairly be laid to the charge of paracentesis thoracis, as one of the deaths (Dyson's) was from phthisis, another (Donovan's) from pneumothorax, and a third (Bray's) from mechanical hydrothorax : for none of which diseases have I advocated the operation as a curative measure. Deducting these three cases, the mortality will be three deaths out of 
twenty-one cases. Had I been desirous to present to the Society the strongest possible case in favour of paracentesis, I might fairly have excluded Dr. Edwin Harrison's and Mr. Phillips' patients, two of whom to my own knowledge were in a hopeless condition at the time when the operation was performed upon them; but, rather than exclude any case, I prefer to give every one which came under my observation, in order that my professional brethren may see that I report the successful and unsuccessful cases with equal faithfulness, and may have data on which to form their own judgment as to the propriety of reviving this very ancient remedy, one which can be traced up to Hippocrates. The cases in the Appendix will show that the success of the operation was directly in proportion to the shortness of the time which intervened between the accumulation of the fluid and the performance of the operation, and that when it was unsuccessful the chief cause of its failure was its being postponed until too late a period: the very fact that, with the exception of one case (No. 24) of pneumothorax, death occurred only where the effusion had been of very long standing, suggests the opinion that the failure of the operation may be attributed to the duration of the disease, the contracted state of the lung, and other changes which the thoracic viscera are known to undergo from the long-continued pressure of the effused fluid, and leads to the conclusion that we ought not unnecessarily to delay the operation a single day. 


\section{APPENDIX.}

Case 1.-The first patient upon whom I saw paracentesis thoracis performed was George Louch, æt. $5 \frac{1}{2}$. As his case was published in the Medical Gazette, by Mr. Woolley, whose patient he was, I need only say, that, in the situation usually selected, the breathing was audible; Mr. Woolley therefore introduced a trochar anteriorly to it, and drew off, on the 15th of March 1833, $43 \mathrm{oz}$. of healthy pus; a considerable quantity more escaped by the side of the canula; air entered freely into the chest during the operation, owing to the struggling of the child; he experienced immediate relief from the operation, but a second accumulation took place, and on the 28th of March 1833, Mr. Woolley again introduced a trochar, and drew off $38 \mathrm{oz}$. of pus; respiration gradually returned over the whole of the left side; at the end of three weeks the heart had regained its natural position, and the boy appeared perfectly well. No internal remedies, except occasional aperients, were employed in his treatment.

Case 2.-Silas Hann, æt. 20, a tailor, was admitted as a patient of mine into the Westminster Hospital, on the 6th of August 1833. He was a dark, unhealthyjooking man, had long been subject to cough, and delicate health. Six weeks bef $r$ re, he had been attacked by rigors, pains in the limbs and general malaise, followed by difficulty of breathing, frequent cough, and an acute pain on the right side of the chest, which was greatly increased by taking a full 
inspiration. For these syinptoms no active treatment was adopted, and he began shortly afterwards to suffer so much from increased dyspnœa and cough, that he was unable to follow his employment. When admitted into the hospital, all the signs of effusion into the right pleural cavity were observed: paracentesis was performed, and six pints of clear serum were evacuated. During the operation, air entered very freely into the chest ; but after it, some respiration could be heard in the lung. On the following day the chest was sore and painful, several cupping glasses were applied to it, and six ounces of blood were abstracted. On the third day the breathing became very distressing, and the chest tympanitic. At the suggestion of Mr. Walsh, who was then our clinical assistant, and who is now practising at Worcester, an exhausting syringe, terminating in a fine canula, was passed into the chest, the wound being then healed. The air was pumped out in a few minutes; and from that time no further accumulation of air or fluid occurred, the respiratory murmur gradually returned, and the patient quickly became convalescent.

Case 3.-Richard Bray, æt. 50, a waggoner, was admitted into the Westminster Hospital, under my care, April 20, 1834, with the following symptoms:laborious respiration, 26 in a minute; orthopnœa; sleep interrupted by frequent starts, and jumping up from fear of suffocation; action of the heart violent; ascites; lower extremities anasarcous; urine deficient in quantity, but not albuminous; the left side of the thorax more distended than the right, 
very dull on percussion at its lower half; bronchial "râles" audible over the greater part of the lung; heart's action irregular and tumultuous, accompanied by a very loud " bruit de soufflet." It appeared from his previous history that, four years ago, he was the subject of acute rheumatism, that he had suffered from palpitation of the heart and dyspnœa upon exertion ever since, that within the last year he had had œdema of the lower, and occasionally of the upper extremities, with troublesome cough and copious mucous expectoration, frequently streaked with blood.

I gave him various diuretic and purgative remedies, without any decided or permanent benefit ; and early in June he was suddenly attacked with very severe dyspnœa, irregularity of the heart's action, and bounding pulse, 137 in the minute. His face was congested with blood, his body was covered with perspiration, and he appeared to be sinking. At his own earnest request, paracentesis was performed on the left side, and $60 \mathrm{oz}$. of clear serum were removed, with immediate relief, the lung appearing to expand at its upper part as the fluid flowed out. The trochar used in the operation was so blunt that it pushed the pleura before it, without perforating it at first : it entered, however, at the second attempt. Notwithstanding the violence used, no bad symptom supervened. He remained in the hospital several weeks afterwards; and, though he had occasionally attacks of severe dyspnœa, he slowly improved, the lung was relieved, the anasarca disappeared, and 
after some time he returned home, and worked in Covent-Garden market, carrving vegetables, until the following November, when he again returned to the hospital with general dropsy, effusion into both pleuræ, and difficult breathing, and died in a few days. His heart was found very much enlarged, the valves on the left side were thickened, and all the cavities contained more or less of fluid.

Case 4.-Charles Dyson, æt. 48, residing in Regentstreet, Westminster, was admitted into the Westminster Hospital, July 9th, 1836, as my patient, suffering from difficulty of breathing, frequent cough, and abundant muco-purulent expectoration. He could only lie on the right side ; the left side hardly moved during respiration: it measured half an inch less than the right, was everywhere very dull on percussion, no respiratory murmur was audible in it, except immediately under the clavicle, but blowing sounds could be heard close to the spine; the intercostals were prominent; the heart was felt beating under the right margin of the sternum. He said his health had not been good for some time, but he could not recollect having suffered from pain in the side; during the last fifteen months he had had frequent attacks of dyspnœa and cough, particularly upon making any great exertion. He was told that paracentesis would afford him the best chance of recovery, though his case was a very unfavourable one. The operation was performed, but there was some difficulty in penetrating the pleura, which appeared to be pushed before the trochar, in consequence, in 
all probability, of its thickened condition : $28 \mathrm{oz}$. of pus were removed, with some relief to his breathing; but the heart did not return to its place, neither could respiration be heard in the left lung. The fluid soon accumulated again; the man did not wish the operation repeated; and, as I could not promise him any benefit from it, I did not press it. He was, therefore, treated with calomel and opium, and afterwards with tonics, iron, \&c., but without any good effect. He became gradually more and more exhausted, and died in about seven months from his admission.

Sectio cadaveris.-The pleura on the left side was very much thickened, and coated in patches with false membrane; adhesions between the pleura costalis and pulmonalis had formed two separate cavities-the inferior had been opened by the trochar, but the superior had not-it contained nearly eight pints of pus; the lung was carnified and incapable of expansion, no tubercles could be detected in it, but the lung on the opposite side was studded with minute crude tubercles.

Case 5.-Catherine Eades, æt. 10, residing in Frederick-place, Hampstead-road, was seen by me, on the 19th of January 1837, in consultation with Mr. Lambert, of Berners-street. She was much emaciated, and was lying on her back, breathing tolerably easily; her pulse was very feeble, 120, her skin cold, and she complained of great debility. The whole of the left side sounded dull on percussion, especially at the middle and lower part; respiration could be 
very faintly heard under the clavicle, but in no other part. The right side sounded clearly on percussion, and respiration was louder than natural: there was no ægophony. The heart was felt pulsating in its natural position, and still more strongly on the right side of the sternum also; she could lie on either side. Mr. Lambert informed me that he had been requested to see her on the preceding. Christmasday, and had found her suffering from pleurisy of the left side; that the more acute symptoms had yielded to the ordinary treatment ; but that, instead of recovering her health, she had become gradually more and more emaciated; her pulse had quickened, febrile exacerbations had come on, with a very troublesome cough. We agreed in thinking that in all probability there was fluid in the left side of the chest ; but we were puzzled to account for the heart being felt so very distinctly at both the right and left side of the sternum, and could only suppose that a distended pleura had pushed the heart out of its place, and now communicated its impulse on the left side, just as a tap given to a distended bladder at one side is felt at the other. We introduced the exploring needle, and the appearance of a few drops of pus proved the correctness of our diagnosis. The child was then too weak to bear an operation. Quinine, ammonia and generous diet were given her; and, at the end of a week, Mr. Lambert withdrew $8 \mathrm{oz}$. of unusually thick pus, resembling thick mucilage, with a common trochar. The wound was closed, but would not heal, and a considerable quantity of puruvOL. XXVII. 
lent matter was discharged through it for four weeks afterwards : at the end of this time it healed. The child's health improved rapidly after the operation; tonics and generous diet were continued, counterirritants were applied to the affected side, and in about three weeks respiration became distinctly audible in the upper part of the affected lung, and by degrees through the whole of it. She had no return of bad symptoms, and a short time ago was in perfect health.

Case 6.-This patient was treated by Mr. W. H. Smith, surgeon to the South London Dispensary, who has kindly furnished me with an outline of his case. July 3rd, 1837, Thomas Rigg, æt. 19, a blacksmith, applied this day for relief. He stated, that some months ago he had been affected with violent cough, accompanied by severe pain in the side, and expectoration, for which he had been bled, blistered, and salivated. He told me his medical attendant had pronounced him in the last stage of phthisis, and said it was impossible he could live many days. He breathed with great difficulty, had a troublesome cough, and expectorated pus : his pulse was 140, face flushed, and his fingers presented the most truncated extremities I ever saw. On examining the chest, I found a preternatural expansion of the left side; upon pressing the intercostal spaces, they felt distinctly distended, and gave me the impression that fluid was contained in the cavity of the pleura; there was also great dullness on percussion, and a total absence of the 
respiratory murmur over that side. I resolved to perform the operation of tapping, believing it to be the only means of saving him. After making an incision through the skin with a scalpel, I cautiously introduced an hydrocele trochar between the sixth and seventh ribs, about their junction with the cartilages, the point where the distension appeared greatest, and drew off about four pints of wellformed, bland, and perfectly inodorous pus. In a few days the irritative fever subsided, under the usual treatment, and afterwards, by the use of a generous diet, and quinine, he rapidly recovered his health and strength, but matter continued to discharge through the wound, which had become fistulous, for many weeks. I have seen this patient to-day, April 6th, 1844 , after an interval of nearly seven years; he appears in good health, is free from cough, and his strength is unimpaired. There is great contraction of the left side, from the dorsal vertebræ to the middle of the sternum. The affected side measures thirteen inches and a half; the sound, or right side, twenty inches.

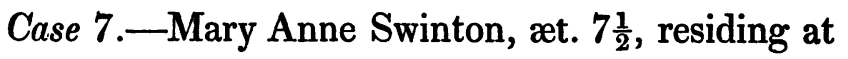
7, Paragon-row, Walworth, was also under $\mathrm{Mr}$. Smith's care, 6 th of July 1837. He states, that his attention was called to this case by Dr. Hughes, who was then his colleague-that after consultation, they felt satisfied there was a collection of fluid in the right side of the child's chest, and decided that paracentesis was called for. Mr. Smith pushed in a lancet through the intercostal space, between the

R 2 
sixth and seventh ribs, near the angles, and drew off about $5 \mathrm{oz}$. of healthy pus. This little patient perfectly recovered, but with a contracted chest.

Case 8.-Joseph Willis, æt. 26, was admitted into University College Hospital, under the care of Dr. A. T. Thomson, on the 17 th of October 1837 . His previous habits had been intemperate, but, with the exception of a slight cough, he had usually enjoyed excellent health, until six weeks ago, when he was attacked with fever, for which he was admitted into the Fever Hospital. On his admission into the College Hospital, he complained of excessive debility, was greatly emaciated, had a severe cough, without expectoration-confined bowels, and slept badly. His tongue was dry and red-the stethoscope indicated the respiration to be natural on the right side, but on the left it was heard only at the root of the lung-pulse sharp, 110.

December 1st.-Yesterday a projection appeared between the fifth and sixth ribs of the left side; the operation of paracentesis thoracis was performed, and $50 \mathrm{oz}$. of pus were evacuated. On the 15th, the respiration had returned immediately under the clavicle on the left side: the orifice formed by the operation continued to discharge freely. He continued to improve slowly, but decidedly, except that he suffered from copious nightly perspirations : the orifice of the operation, and a wound which had opened two ribs below, continued to discharge. The resonance on the left side extended gradually below the clavicle, as did also the respiratory murmur, 
which at length became audible below the mamma : the side flattened in a remarkable degree-the discharge almost disappeared. On the 14th of February 1841 , he was attacked with acute bronchitis, and died on the 17th, exactly three years and ten days after the operation of paracentesis thoracis had been performed.

Sectio cadaveris.-Body examined twenty-four hours after death. The emaciation was considerable - the left side of the thorax was greatly flattened, and the spine was curved to the right side. On opening the chest, the heart was seen lying towards the right side, and almost over the spine; the right lung was nearly of its natural size, and weighed $2 \mathrm{lb} .4 \mathrm{oz} .2 \mathrm{dr}$; ; the left was very much shrunk, weighing only $10 \mathrm{oz} .7 \mathrm{dr}$.: throughout the substance of the right lung were scattered many small white granules, about the size of a millet seed, which had, however, no appearance of tubercles, but resembled inspissated pus, contained in cysts, having no communication with one another, but apparently connected with the bronchi. The space at the bottom of the left thoracic cavity contained about 3 xii of foetid purulent matter, and lying loosely in this fluid was a piece of carious bone, apparently part of one of the ribs. . It was about an inch long, and half an inch broad. The whole of the pleura, on this side of the chest, was coated with a false membrane, nearly half an inch thick, and of cartilaginous firmness; the free surface of the membrane was black-the ribs were greatly 
hypertrophied, being nearly an inch and a half in thickness, very spongy, and vascular; the left lung, beside being much shrunk, was adherent behind through its whole length, and below to the diaphragm. A small portion of its anterior tissue was pervious to air, and crepitant, but the remainder was a mass of tough, nearly homogeneous, dark-coloured tissue, except the bronchial tubes, the larger of which were still pervious, although much lessened in diameter; the greater number of the smaller were obliterated ; the pericardium contained a small quantity of clear serum; the heart weighed $8 \mathrm{oz}$., and was small in size-nevertheless, the substance of the left ventricle was slightly hypertrophied, and the membrane lining it somewhat opaque.

This patient lived long enough to permit the almost complete obliteration of the pleural cavity to be effected by the agglutination of the granulating membranes; a small portion, however, remained in the immediate neighbourhood of the opening made by the trochar, where the surfaces had not adhered, and still continued to secrete unhealthy purulent matter, and evinced but little disposition to heal.

Case 9.-Peter Murray, æt. 28, was admitted into the Westminster Hospital on the 19th of December 1837. He was an anxious-looking man, of a sallow complexion and unhealthy appearance, and complained of cough, great difficulty of breathing, acute pain in the right side and different parts of his body, great prostration of strength, and relaxation of the bowels. Respiration was very indistinct over the 
whole of the right lung, and percussion gave a very dull sound. Respiration was loud over the left side. He said he had enjoyed good health until about fourteen days ago, when, after exposure to cold, he was seized with shivering and pain of the right side. He was cupped on the painful side to $10 \mathrm{oz}$., and took 2 gr. of calomel, with ipecacuanha and conium, at first every four hours, and afterwards every two hours, until the 28th of December, when the effused fluid not appearing to diminish, an exploring needle was introduced, and pus oozed out. The operation was now performed with a trochar, and $10 \mathrm{oz}$. of purulent matter were evacuated. The relief afforded him was greater than could have been expected from the small quantity of fluid withdrawn. Respiration could be perceived at the upper part of the lung, but ægophony was heard under the right scapula. From this time he continued to improve, was put on full diet on the 3rd of January 1838, respiration became more audible, and his condition was so altered that no more reports were made, and he went out well about the middle of January.

Case 10. Hardwicke, æt. 9, had an attack of pleurisy in the year 1838, which was followed by the ordinary symptoms of effusion, notwithstanding that active treatment had been adopted. The left side was punctured with a flat trochar, and about half-apint of pus was drawn off. On the following day, the wound being closed, and more fluid being detected in the chest, an opening was made with a common abscess lancet, and about half-a-pint more 
was evacuated. The wound was now left open, and pus continued to be discharged through it daily for three months, but gradually decreasing in quantity until it ceased altogether, when the wound healed spontaneously. During the first few weeks the child suffered from constitutional disturbance, but afterwards recovered her health and strength : she is now perfectly well, and the respiration is restored in the left lung.

This was a case of Mr. Thompson's, of Westerham ; and it was communicated to me by Mr. Buller, who was his partner at the time the operation was performed.

Case 11.-B. D., æt. 62, was a patient of Dr. Macreight's, in the Marylebone Infirmary, in 1838 ; but was left in charge of Dr. Edwin Harrison, and was tapped by Mr. Benjamin Phillips, who has kindly communicated to me an outline of the case. The man principally complained of shortness of breath and swelling of the ancles, with great debility. Upon examination, the heart's impulse was not observable on the left side of the sternum, but it was distinctly perceptible on the right, less distinctly under the sternum also. It was evident that a considerable quantity of fluid existed in the left cavity of the chest, and it appeared probable that it had caused displacement of the heart. The disease had been evidently of long standing, and the man was too much debilitated to expect a favourable result; but, as the operation was sure to afford him great relief, the chest was tapped with a trochar, and $64 \mathrm{oz}$. of 
transparent straw-coloured fluid escaped. Immediate relief followed, and in the course of a few days the heart was found to have inclined considerably towards the left side. Again the fluid accumulated, and the operation was repeated with similar results. Every drop of fluid which was within reach was allowed to escape, and no precaution was taken to prevent the entrance of air, which completely occupied that side of the chest, but no inconvenience was experienced from its presence : in a few days it seemed to have disappeared. The heart now resumed very nearly its proper place, and for nearly three months there was little tendency to re-accumulation. After that, the embarrassment returned, he was again tapped, lingered on a few weeks, and died : no opportunity was afforded for examining the body. I give this and the following case as being illustrative of the obstacles which extreme debility opposes to the cure by an operation, and of the effects of postponing paracentesis until too late a period. They ought not to be calculated amongst those which appear to show the unfavourable results of the operation, as Mr. Phillips from the first had an unfavourable opinion, as well as Dr. Edwin Harrison and myself.

Case 12. — Perkins, æt. 53, was a patient of Dr. Edwin Harrison's, in the Marylebone Infirmary, in 1838, and was operated upon by Mr. Benjamin Phillips, to whom I am indebted for the following outline of the case. The man had diseased heart, and the usual signs of hydrothorax of the right side of the 
chest. $62 \mathrm{oz}$. of transparent straw-coloured serous fluid were removed. The relief was immediate, and no inconvenience followed the operation. In two months effusion had again taken place : he was tapped a second time, and $56 \mathrm{oz}$. of equally transparent fluid were removed. It was rather higher coloured; and, upon the addition of nitric acid, yielded a larger quantity of albumen than the former fluid. Two months later it became necessary to tap him a third time, but only $41 \mathrm{oz}$. of fluid were then procured. The fluid was in all respects similar to that yielded on the previous tapping. The relief was less decided on this than on the former occasions : the oppression was less completely relieved, and he died at the expiration of about five months from the first tapping. The examination after death revealed a curious circumstance : a horizontal septum separated that side of the chest into two complete compartments; the lower was emptied, but in the upper, between 30 and $40 \mathrm{oz}$. of fluid were found.

Case 13.-C. E., æt. 43, was admitted a patient of the Marylebone Infirmary in 1839, with symptoms of chronic disease of the liver and effusion into the right side of the chest, for which the ordinary means were tried without success. The difficulty of breathing having become very urgent, the chest was tapped by Mr. Phillips, and $120 \mathrm{oz}$. of tolerably transparent deep citron-coloured serum escaped. The relief was instantaneous and complete. In the course of a month the breathing again became difficult, tapping was had recourse to, and $73 \mathrm{oz}$. of similar fluid were 
evacuated, with similar but less permanent relief. In the course of twelve days he died, but was not examined after death. Mr. Phillips adds, the only appreciable difference between the fluid of the first and second tapping was, that upon the use of heat and nitric acid, a larger quantity of albumen was detected in the latter than in the former.

Case 14.-The following case also came under the care of Mr. W. H. Smith, after effusion had taken place, and he did not know what measures had been adopted for the cure of the pleurisy.

August 1839 . —, æt. $3 \frac{1}{2}$, residing at 3, Spring-place, Wandsworth road, had all the symptoms of effusion into the left pleural cavity. Her mother stated that she had been suffering some time from a harrassing cough. The left side of her chest was decidedly prominent, and the intercostal spaces appeared distended. Mr. Smith introduced a lancet, and drew off $4 \mathrm{oz}$. of sero-purulent matter. This little patient required a great deal of care; but, with generous diet, tonic medicines, and good nursing, she ultimately recovered her health and strength, but her chest remained very much contracted.

Case 15.-Sampson Glover, æt. 28, was admitted into the Westminster Hospital, as my patient, in May 1840. He was a leather-dresser, of marked strumous diathesis, and moderately temperate in his habits. Eight months ago, after exposure to damp and cold, he was attacked with acute pain on the left side of the chest, cough, and great dyspnoea, for which the only treatment employed was an occasional dose of 
purgative medicine; he was so ill that he was confined to bed for some time, but at the end of a month he was able to resume his occupation. Ever since his supposed recovery, he has been subject to frequent attacks of dyspnœea and cough, with acute pain in the affected side, painful respiration, and palpitation of the heart: he has lately lost flesh very much.

His face is pale, conjunctiva blanched, fingers attenuated and clubbed, skin perspirable; he lies usually on his back, sometimes on his left side, but never on the right; he suffers much from dyspnœa, which is aggravated by change of posture, and troublesome cough, particularly on first lying down in bed-he expectorates a good deal of transparent mucus. Pulse 88 in the erect posture, feeble but regular.

Physical signs.-Respirations 36, inspirations prolonged. The right side of the chest expands freelythe left side is nearly motionless; it measures three-quarters of an inch more than the other. The intercostal muscles are nearly on the same plane with the ribs; on placing the fingers of one hand in one of the intercostal spaces, and percussing with the other hand below the margins of the ribs, fluctuation can be perceived; the dullness is uniform in every part of this side, except immediately under the clavicle: there is no vesicular respiration, but harsh bronchial sounds are audible between the scapulæ, close to the spine-vocal resonance is increased at the two superior thirds of the side, and 
in the axillary space, where it resembles the sound of punchinello. Respiration on the right side is puerile: the heart cannot be felt on the left side, but its apex is felt pulsating about two inches below the right nipple.

Three days after his admission, the operation was performed, and $5 \frac{1}{4}$ pints of high-coloured serum were withdrawn, the specific gravity of which was $1 \cdot 20$; whilst the fluid was escaping, the heart was observed to glide towards its natural situation, and when the chest was emptied, its apex was felt at the ensiform cartilage : air passed freely into the chest towards the close of the operation. In two hours he was able to lie on the right side. Respirations 30 - the left side sounded as clearly as it usually does in pneumothorax.

Next day, May 15th, the position of the heart was in the median line, tubular respiration could be heard as low as three inches and a half beneath the left clavicle, and the tympanitic sound was much less marked.

May 18th.-Complains of occasional pains about the left side, with some dyspnœa; the cough and mucous expectoration continue-the heart is now felt at the right side of the sternum-the dullness on percussion occupies a larger space than it has done since the operation: he walks out for a few hours, but any great exertion produces severe dyspnœa.

May 19th.-Dullness extends still higher; breathing more difficult. He complains of acute pain at the 
lower part of the left side of the chest : pulse more frequent-feels very weak.

May 23rd.-No doubt now remaining that fluid had again accumulated, he was tapped, and three pints of serum, with small flakes of albuminous matter floating in it, were withdrawn.

May 24th.-Was much relieved by the operation; the intercostal muscles now act during respiration; the air which entered yesterday has not quite disappeared.

May 27th.-Appeared to improve until to-day; his respiration is now hurried, and the physical signs of fluid have again appeared. He remained in the hospital only a few days afterwards, being anxious to go into the country. No marked alteration had taken place in his symptoms, excepting that the intercostal muscles, from being on the same plane with the ribs, had become very prominent. He had scarcely arrived in the country, when his sufferings increased so much, that he requested to be tapped again; the operation, however, was not performed, and he quickly sank. Mr. Martyn, of Mortock, under whose care he was, thus describes the postmortem appearances : "The left pleural cavity contained fourteen pints of sero-purulent fluid, having a fotid odour. The left lung was completely collapsed; it adhered to the upper part of the mediastinum, and was about four inches long and two broad; it weighed about 3 oz.; its outer surface was covered with adhesive matter. The pleura costalis much thickened, and covered with coagulated 
lymph. The pericardium was forced into the right side of the thorax, and contained about half a pint of serum. The right lung was much compressed, its inferior lobe congested, and its surface covered by old pleuritic adhesions."

Case 16.-James Spader, æt. 55, a strongly-built Scotchman, was admitted into the Westminster Hospital, under my care, on June 2, 1840. His employment was that of a lapidary; his previous health had been good, and his habits temperate. Three months ago he had been attacked by acute pain at the lower and posterior part of the left side of the chest, accompanied with febrile disturbance and cough. He was not bled, being supposed to have disease of the kidney. In about a week the pain abated, but did not leave him for a month: at the end of which he began to suffer from increased dyspnœa and cough, with great emaciation. Before his admission he had taken mercury freely for some weeks. His present symptoms are, general febrile disturbance, feeble and quick pulse, flushed face, tongue covered with a white mucous secretion, apparently the effect of ptyalism. He has a frequent cough, with copious mucous frothy expectoration, is unable to lie for any length of time on the right side, and complains of shortness of breath, especially on moving. The physical signs are, dullness on percussion, over the lower threequarters of the left side of the chest, where vesicular murmur is wanting, and is replaced by distant tubular respiration; the vibratory thrill communicated by the voice is lost ; there is some bronchophony, 
but no ægophony. The intercostal muscles of this side do not act, and they appear somewhat retracted ; the infra-clavicular region is rather prominent, and is resonant on percussion, but the respiration is harsh and bronchial. On the right side, percussion elicits natural resonance-respiration is distinct throughout, but in the infra-clavicular region more loud and puerile.

For the first fortnight after his admission his treatment consisted of generous diet, tonics, and occasional stimuli, which were required by his depressed condition. His general health improved, the febrile excitement ceased; but no diminution of the quantity of pleuritic effusion appearing to take place, he was tapped, and $105 \mathrm{oz}$. of transparent serum were taken away. On the next day the report was-" Expresses himself much relieved, is able to lie on either side, cough less frequent; percussion now elicits a certain degree of resonance, and bronchial respiration can be heard in several spots anteriorly, but there is no return of vesicular murmur." During the succeeding six weeks, the daily reports record his progressive improvement : the chest contracted nearly an inch, vesicular respiration returned at the apex of the lung, but in no other part. He suffered much from dyspeptic symptoms, had but little desire for food, his spirits became depressed, and he said he knew he should never leave the Hospital alive. At the commencement of the eighth week he was suddenly seized with a fit resembling epilepsy, and died in five minutes. 
Sectio cadaveris.-The lung on the right side was of a light colour, distended with air, perfectly crepitant, and studded with minute pearl-like or semi-transparent bodies, closely resembling, in size and distribution, the earlier forms of tubercular deposit. The left lung presented a very different appearance, being much reduced in size, of a very dark colour, generally carnified, containing no air, except at its apex, and covered at its lower threefourths by false membrane, which was remarkably tough, of a white colour, and nearly a quarter of an inch thick in some parts. The lung was attached to the pleura costalis by long adhesive bands of considerable strength. The pleura contained about $2 \mathrm{oz}$. of fluid, with small masses of coagulable lymph floating in it, and scarcely presented a vestige of its original structure, being covered on its free surface with large asperities, or papillæ, which gave it a granulated appearance. The heart was small and flabby. The friends would not allow the brain to be examined.

Case 17.-William Sharpe, æt. 38, residing in Wardour-street, a green-grocer, was seen by me, in consultation with Mr. Odling, of Oxford-street, on the 24th of August 1840. He appeared to be a well-made man, but much out of health, and so feeble that he could not leave his bed. He said he had been in good health until the beginning of the month, when he went with his cart into the country, and was there seized with pain in the head and right hypochondrium, with a troublesome cough, which obliged 
him to return home and to consult Mr. Odling. He was treated in the usual way, without relief. When I saw him, his symptoms were as follows : frequent short cough, shortness of breath on the least motion, with loss of appetite and great depression of spirits. He says he is sometimes seized with paroxysms of difficulty of breathing, which oblige him to sit up immediately in bed : after a while this subsides, and he feels comparatively easy. His inspirations are short, but his respiration is not hurried so long as he lies quiet. The right side of his chest moves very little; the intercostal spaces are well marked; there is no appreciable difference in the measurement of both sides. The right side sounds very dull on percussion anteriorly and posteriorly, nearly as high as the clavicle; no vesicular respiration can be heard in the lung of this side, but a loud blowing sort of breathing can be perceived; there is no ægophony ; he can lie equally well on both sides ; respiration is puerile on the left side. We $e_{\text {agreed on }}$ the propriety of introducing the exploring needle : a few drops of serum appeared in the groove. We therefore tapped him immediately, and drew off nearly four pints of clear serum. He was immediately relieved : the wound was closed, and in two days respiration was perceived in the lung, and became more distinct daily. He continued to take a mixture of nitre and carbonate of soda, and on the second week in September he was free from any difficulty of breathing, but had a small quantity of albumen in his urine : this soon disappeared, and in 
October the respiration in the right lung was nearly as good as in the left. This patient's recovery was complete.

Case 18.-James Wray, æt. 40, an unhealthy-looking man, residing in Palmer's-village, applied for relief at the Westminster Hospital, on August 25, 1840, with all the symptoms of effusion into the pleura.

He had been employed as an armourer at the Eglinton Tournament, where he earned money enough to enable him to spend the ensuing six months in almost constant intoxication. In this state, about a month ago, he passed a night in the streets, exposed to continued rain. Next day he was attacked with rigors, sickness, and pains in his limbs, which were speedily followed by febrile symptoms, and an acute pain at the upper and anterior part of the left side of the chest, with cough and painful respiration, which confined him to his bed. No treatment was employed ; nevertheless, he recovered, in ,about a week, sufficiently to get about. Ever since that attack he has suffered from dyspnœea on slight exertion. His respiration is now hurried and difficult; he suffers from a frequent short cough, paroxysms of dyspnœa, and great depression of health and spirits; his face is pale and anxious; pulse feeble, frequent, and irritable, 120. The right side of his chest expands much more freely than the left, the intercostal muscles of which scarcely act at all. The left side of the chest gives an uniformly dull sound on percussion, no respiratory murmur can be heard in it ; but the respiration on the right side is 
puerile. Above the fifth rib there is marked resonance of the voice on the affected side, and the punchinello sound in the left axillary region. The infraclavicular region of the left side is prominent; but the intercostal muscles are not so; the apex of the heart beats against the ensiform cartilage, but its sounds are natural.

A fortnight was allowed for the trial of remedies, but no improvement having been made in his condition, the operation of paracentesis was performed on the 9th of September, and $4 \frac{1}{2}$ pints of clear straw-coloured serum were evacuated. $\mathrm{He}$ expressed himself greatly relieved, and his respiration became much less hurried. Eight hours after the operation his pulse was 100 , in the recumbent posture. Respiration 28, skin cool and soft, left side expands more freely than before. Resonance much improved in the upper portions of the chest-still wanting in the inferior part. The air can be heard passing into the lung, as low as the ninth rib, on his taking a deep inspiration. The following day he had a slight return of pleuritic pain, which was relieved by a blister. Towards evening, symptoms resembling delirium tremens came on, and they became so much worse next day, that large doses of hyoscyamus were given him at short intervals, until he was relieved.

September 16th.-His respiration is calm and easy, his general health much improved, cough gone, and he is anxious to resume his work. The chest sounds clearly on percussion, except at the lower 
third, where there is still dullness. Vesicular respiration is heard in the upper part of the lung; towards the base, the respiration is harsh and bronchial. On the 28 th, he was so well as no longer to require medical advice. In the beginning of the following December, he returned to have his chest examined, and vesicular respiration could be perceived, nearly as low as the very bottom of the lung.

Case 19.-Edward Evans was admitted into the Westminster Hospital, in November 1840, under the care of Dr. Burne, with the usual symptoms of inflammatory hydrothorax, and displacement of the heart to the right side. Paracentesis was performed, a few ounces of serum were withdrawn, and a large quantity of fluid remained in the chest. Six days afterwards, the chest was again punctured with a trochar, but not more than 8 ounces of fluid escaped; the greater portion of it having been absorbed during the interval which elapsed between the two operations.

Case 20.-George Cooper, æt. 28, a carpenter, applied to the Westminster Hospital, in January 1841, suffering from effusion into the chest. He was an emaciated, strumous-looking man, and had been constantly exposed by his employment to damp and cold. Six weeks ago, after having been working out of doors, in bad weather, he was seized with rigors, which were soon followed by inflammatory fever, and pain in the right side of his chest, but not of an acute kind. No remedies were employed, and 
at the end of a week he attempted to resume his work, but found himself unable to do so, from his great debility, and the dyspnœa which immediately followed exertion. He has been gradually getting worse ever since. His respiration is hurried: he now lies on his right side, which is nearly motionless; its intercostals are not prominent, but the infra-clavicular region is remarkably so. The two inferior thirds of this side give a very dull sound on percussion, and no respiration can be heard in any part, except in a small space above the spine of the scapula : there, it is harsh and bronchial. There is no marked resonance of the voice, nor vibratory thrill from speaking. Heart's action hurried, and its sounds occasionally indistinct. He suffers from frequent cough, nightly perspirations, dyspnœe, occasional startings, and a constant distressing feeling of oppression about the heart. Paracentesis was performed a few days after his admission, but a violent paroxysm of coughing, which came on after a small portion of the fluid had been withdrawn, drove the canula out of the wound : 30 ounces only of clear yellow serum were evacuated. Four hours after the operation, respiration could be heard in the upper half of the right lung, but in the lower half there was great dullness, and absence of respiration. His symptoms improved for a fortnight, but then remained stationary; on examination, it was found that fluid still remained in the pleural cavity. The operation was again performed, and $25 \mathrm{oz}$. of serum, similar in quality to the last taken, were abstracted. 
From that time he improved rapidly. Respiration became audible in every part of the chest, but it was more bronchial at the lower than at the upper half of the right lung. He had no return of the disease. In this case, as in the majority of the others, air entered freely into the pleural cavity, during the operation, but no bad effects followed.

Case 21.-William Crichton, æt. 34, a very pallid, delicate-looking man, was seen by me, in consultation with Mr. Beck, of Marylebone-street, on the 10th of February 1841. We found him labouring under all the symptoms of pleuritic effusion. He said that he was a man of regular habits - that a fortnight ago he had been attacked with acute pain of the right side of the chest, without any well-marked febrile symptoms : his breathing had become short, and he had lost his strength. On examination, we found the right side of the chest very dull on percussion, and without any sound of respiration, except in a small space between the scapulæ. I recommended the removal of the fluid by tapping; but Mr. Beck, who had seen the nature of the case most clearly from the first, and who had been exhibiting mercury in small doses, with diuretics and local counter-irritation, wished to give these remedies a little further trial; his dyspnœa, however, became greater, and his strength more reduced; the operation, therefore, was performed on the 17th of February, and $3 \frac{1}{2}$ pints of clear yellow serum were drawn off: some flakes of coagulated matter appeared in the last portions. Immediately after the 
operation, he was seized with a paroxysm of coughing, but when it was over he said he felt much relieved. Four hours after the operation his respiration had become easy, and some air could be heard entering the right lung: his pulse remained quick and fluttering.

April 10th.-Respiration much more evident, especially at the posterior part of the affected side.

April 21st.-Respiration audible over the whole of the right side of the chest, but the vesicular murmur is not everywhere distinct: some dullness on percussion still remained, but not sufficient to make us believe that fluid had again been effused. His general health was rapidly improving; no contraction of the chest took place. In this case, the prominence of the infra-clavicular region on the affected side was well marked, but no protrusion of the lower intercostals existed. This man was admitted into the Westminster Hospital, some time after the operation had been performed, for sciatica, and there was then no evidence of his pleuritic disease.

Case 22.-April 30th, 1841.-J. Rodwell, æt. 58, residing at 7, Richard-street, Liverpool-road, applied to Dr. Frederic Bird, with symptoms of effusion into the chest. He was a porter by occupation, of temperate habits, and, previously to his present illness, had enjoyed good health. His countenance expressed great anxiety ; his colour was pale-the conjunctivæ blanched; he was unable to lie on the left side, and for a short time only on the right. Dyspnoea was caused by the slightest exertion. He coughed fre- 
quently, but seldom expectorated-he had febrile accessions every evening. Pulse 90, feeble and irritable. Percussion elicited a dull sound over the whole of the left side, excepting the part immediately below the clavicle, where there was some resonance. In this situation, respiration could be heard, but it was absent in every other part of that side of the chest ; no vocal resonance could be perceived. On the left side, respiration was puerile, and percussion was natural. Three weeks before, he had been attacked by febrile symptoms, followed by cough, dyspnœa, acute pain of the right side of the chest, aggravated by taking a full inspiration, together with all the ordinary symptoms of pleurisy. Leeches were applied to his chest, internal remedies were given him, and his more urgent symptoms were relieved, but he continued to suffer from cough, frequent attacks of dyspnœa, and great prostration of strength ; he was, however, considered cured by his medical attendant, who attributed his cough and difficulty of breathing, to weakness. The ordinary treatment was adopted by Dr. Frederic Bird, and continued up to the 29th of May, when his health appearing to be improved, but no diminution having taken place in the quantity of the effused fluid, a small, very fine exploring trochar was introduced; pus appeared, and paracentesis was performed with a trochar of larger size, but still a very small one; 90 ounces of thick, and not unhealthy-looking pus were removed-the first few. ounces passing through the canula with considerable force. A large quan- 
tity of air passed into the chest towards the end of the operation, during a violent fit of coughing, but no inconvenience resulted from it: the pulse scarcely rose at all. The relief afforded was very great. Coarse respiration could be heard anteriorly, as low down as the third rib, immediately after the evacuation of the fluid, and he was able to lie on his left side. On the next day, 30th of May, respiration was more distinct, and could be heard as low as the fifth rib : his appearance, also, was much improved. On the 5th of June, he was able to go out, but respiration had not returned at the lower third of the lung, and the right side of the chest appeared contracting. His convalescence was retarded by an attack of bronchitis, from which he suffered severely for some weeks; but in August he was sufficiently recovered to resume his employment. His chest was then somewhat contracted at the lower part of the right side. Respiration could be heard distinctly over the upper two-thirds of the right lung, where it was almost natural, but over the lower third it was absent. In the November following, he was in perfect health.

Case 23.-L. R., æt. 17, of a scrofulous diathesis, applied for medical advice to Dr. Frederic Bird, in November 1842. She was then suffering from diarrhœa, with tympanitis, and recovered slowly, by the use of ordinary remedies. Her chest was examined at this time, and the apex of the right lung was found duller on percussion than that of the left. The respiration was less distinct on the right than on 
the left side; but there were no unnatural sounds. In February 1843 she began to complain of some difficulty of breathing, and slight cough, but without expectoration. The whole of the right side of the chest was then dull on percussion, particularly at its inferior two-thirds. Respiration was inaudible everywhere, except at the apex; there it was harsh, distant, and tubular. There was no ægophony, but there was increased resonance of the voice at the apex of this lung, and some crepitation after a deep inspiration. For six weeks, the ordinary remedies were employed, but without success ; when, finding that her general health was beginning to be impaired, Dr. F. Bird punctured the chest with a trochar, between the fourth and fifth ribs, and drew off three pints of serum, which afforded her great relief : air entered the chest during the operation, but it produced no inconvenience. The lung did not expand immediately after the withdrawal of the fluid, but on the second day respiration could be heard all over the superior two-thirds of the lung affected, but at the apex it was still deficient and harsh, with some crepitation. Notwithstanding the employment of general remedies, of which counterirritation formed the most important part, the fluid again accumulated, and on the 12th of July she was tapped again, and three pints of serum were evacuated. The chest gave the same physical signs after this, as after the first operation. On the 25th of August she was tapped a third time, and four pints of fluid were evacuated, which was slightly 
turbid. Diuretics, iodine, and mercurials, had been used in the interval. On November 20th she was tapped the fourth time, there being evidence of a still larger quantity than before having accumulated; and the intercostal spaces, which until now had not been prominent, having become much distended. Six pints of thick pus were removed, by a large trochar, with very marked relief. No expansion of the lung appeared to take place, but in a few days the thoracic parietes began to contract. Nearly five months have elapsed since the last operation was performed; no fluid accumulated after it : but little or no respiration can be heard in the lung; the patient, however, appears to breathe freely, and looks well. The right side measures one inch less than the left; the intercostals are retracted, and act but little during inspiration. The remedial measures employed after the last tapping were chiefly dietetic; small quantities of animal food were given at short intervals, and good air and moderate exercise were recommended; five grains of blue pill were given every night, until the gums had become slightly affected.

Case 24.-B. Donovan, æt. 38, was admitted into the Westminster Hospital, on the 16th of January 1844, with marked dullness below the right clavicle, and symptoms of rather acute bronchitis, which were so much relieved by cupping, and conium with ipecacuhana, that he was able to be up on the 24th. On the 28th, a slight tinkling sound was heard on the left side of his chest for the first time, and when he 
spoke, his voice appeared like the ringing of a vibrating glass, or as if he was speaking into a bottle. The inferior part of this side of the chest was very dull on percussion, and respiration was there inaudible. The peculiar sounds were loudest about the inferior angle of the scapula, and were much more distinct at some times than at others, but occasionally the amphoric speaking could not be heard at all. The first week in March, the dullness on the left side reached nearly as high as the nipple, above which the chest was tympanitic. This side measured three-quarters of an inch more than the other, and no respiration could be perceived in it. The pulsation of the heart was felt a little to the right of the sternum. I passed a grooved needle, and perceiving some drops of fluid escaping, I drew off fifty-six ounces of turbid serum, with a small trochar; this afforded great relief to the dyspnœa. On the 12th, the difficulty of breathing returned, when I requested Dr. Edwin Harrison to see him. The left side of the chest was tympanitic above the nipple, and very dull at its lowest part ; it appeared more prominent, and measured half an inch more than the right. Respiration was strong, but not expansive nor vesicular, above the nipple, and distant below it; slight amphoric breathing could then be perceived. On the right side there was marked dullness under the clavicle, and above the spine of the scapula, which decreased gradually downwards, until it became clear and emphysematous. Under the clavicle there was strong re- 
sonance of the voice, with a sound of air rushing in. He became worse by degrees, his countenance more anxious, and breathing more oppressed. The left side of the chest, generally, sounded preternaturally clear. Respiration was inaudible posteriorly on that side, below the angle of the scapula; and when he took a full inspiration, a splashing sound was heard, as if a drop of water had fallen from a height into a metallic basin. To relieve his breathing, Mr. Phillips tapped him with a small trochar, and drew off about 7 ounces of green serum : a piece of bougie was left in the wound, at my request, in order to keep it open. He was very little relieved, and, despairing of his recovery, he left the hospital, and died at home on the 27 th.

Sectio cadaveris, forty-eight hours after death.The anterior part of the left side was tympanitic on percussion. On cutting through the cartilages of the ribs of that side, highly fœtid gas escaped. On removing the sternum, the left pleural cavity appeared, at first sight, empty ; about a pint of seropurulent matter lay at the bottom of it-and the lung, reduced to a size little more than that of the closed hand, appeared to be bound down to the spine, but on examination it was found to adhere posteriorly only. On introducing the nozzle of a pair of bellows into the left bronchus, the lung was found permeable to air, and could be dilated to about three-fourths of its usual healthy size; but it soon collapsed, with a sound similar to that of air escaping from a small orifice. A minute aperture, 
about the size of a pin's head, with ulcerated edges, was discovered on the anterior surface of the lung, near its apex, through which air escaped. The opening communicated with a tubercular mass, lying near the surface of the pleura, about the size of a walnut, which had been partially excavated, and into which a bronchial tube opened. There were a few smaller tubercular masses near the apex. The lung itself was congested with blood, firm on pressure, and of a deep red colour. We were not permitted to examine the body further. 